\title{
Measurement in jejunal biopsies by computer-aided microscopy
}

\author{
GERARD SLAVIN, CHRISTOPHER SOWTER, KENNETH ROBERTSON, \\ SUSAN MCDERMOTT, AND KEITH PATON
}

From the Northwick Park Hospital and Clinical Research Centre, Harrow, Middlesex, UK

SUMMARY A method of morphometric analysis of jejunal mucosa using computer-aided microscopy is described. It is based on the technique of interactive computer graphics with definition by the observer of areas and lengths for measurement, but it also includes automatic measurements based on grey-level segmentation. The analyses are performed rapidly and efficiently. The technique is applicable to the analysis of biopsy tissue from many sites.

Measurement is important in the assessment of jejunal mucosal biopsies. The appearances of normal jejunal mucosa are clearly distinguished from those of the untreated coeliac patient with a 'flat' biopsy. However, in other diseases the changes are intermediate between these two extremes, and in an individual case of coeliac disease with sequential biopsies it is important to be able to monitor in objective terms response of mucosa to therapy. Descriptive observations based on visual assessment of the mucosal biopsy are not sufficient and measurements are necessary. Measurements of jejunal mucosa have been made of villous height and mucosal thickness using projected images ${ }^{12}$ and by eye-piece micrometer. ${ }^{3}$ These have largely been replaced by techniques based on point counting and intercept measurements using an eyepiece grid. While these methods have provided important information 45 for specific problems they are less often applied in routine practice because they are tedious and require the observer to perform the counting or measuring procedure, and there may be limitations due to interobserver differences. A combination of point counting with computer manipulation of the recorded data has been described by Meinhardt et al., ${ }^{6}$ who drew a camera lucida image of the histological field on to 80-column computer cards which were read by optical mark reader and the data were fed into a minicomputer. Chapman et al. ${ }^{7}$ reported a method of computer analysis based on a tracing of a projected mucosal image. There is clearly scope for further development of computer-aided microscopy both in structural

Received for publication 8 August 1979 analysis of the microscopic image and also in the rapid measurement of the defined structural elements within that image.

Computer analysis of microscopic images using commercially available systems is usually based on the separation of the image into its structural components by means of the grey-levels each structure produces within the image $^{8}$ and the gathering of numerical data from features displayed by the images such as areas, perimeters, and diameters. In such grey-level discrimination it is assumed that, for example, there is a particular 'threshold' such that all points with density greater than the threshold belong to a structure of interest and all other points belong to the background. In the biomedical field, computer measurements have been made of many tissues including muscle, ${ }^{9}$ lung, ${ }^{10}$ parathyroid gland, ${ }^{11}$ and lymphocyte nuclei. ${ }^{12}$ The technique of grey thresholding, however, is inadequate in difficult problems, and separation of an image into its structural components by this method and measurement of the structures are impossible in many biological cases. An alternative approach is to use an analytical system which allows the observer to outline the structures of interest using a 'light-pen'; this permits better definition than simple editing of a previously segmented image. The structures so defined are rapidly measured by the computer. The Magiscan image analyser is such a system based on a Data General Nova mini-computer, a microprocessor specialised for image analysis. A television camera records the microscopic image, which is displayed on a monitor. The 'light-pen' allows the observer to interact with the image in accordance with a specific 
programme written for the particular problem. In this paper we describe the application of the Magiscan system to the analysis of jejunal mucosa biopsies.

\section{Method}

Jejunal mucosal biopsies were taken perorally under radiological control using a Crosby capsule from a standard site in the proximal jejunum. Tissue was obtained from 18 adult patients with untreated coeliac disease and from 20 adult patients investigated for small bowel disease which showed no histological abnormality including no increase in the number of intraepithelial lymphocytes. These were regarded as 'normal' biopsies for the purposes of comparison. The specimens were fixed in $10 \%$ formol saline and embedded in wax. Particular care was taken during the embedding process to orientate the specimens correctly so that oblique cuts were avoided. All the measurements made were on the processed tissue. No allowances were made for the tissue artefacts of shrinkage and distortion during fixation and sectioning, but all biopsies were identically processed. Each section was cut at 3 microns. The sections were then examined on the Magiscan Image Analysing System as follows.

The image of the mucosal biopsy is displayed on the monitor screen of the Magiscan (Fig. 1) and examined with a haematoxylin and eosin preparation, producing a black/white image with varying shades of grey levels. Standard selective stains are used to produce greater tonal contrast to identify particular cells or tissue components, and contrast may be further enhanced by the use of filters. Using the 'light-pen', the observer outlines the outer epithelial boundary of the biopsy (Fig. 2). At the edges of the active frame, or at any intervening point if only a portion of the biopsy is under scrutiny, vertical lines are drawn up with a 'light-pen' to delineate the field which is then completed by a line drawn along the image of the muscularis mucosae. The observer then defines in a similar manner the inner border of the epithelium. If some crypts are cut obliquely, then included islands of epithelial cells contained within the lamina propria are also defined in this way. Portions of obliquely sectioned villi, apparently separated from the bulk of the specimen, are similarly included.

At this point the observer has defined an area of mucosa and, within it, epithelial or lamina propria components together with the associated muscularis mucosae. Each of these components may then be measured by the computer. Within the delineated frame further measurements may be made of specific cells or tissue components. These may be automatic if the staining technique allows clear discrimination by grey levels (Fig. 3). In many instances the grey-level differences do not accurately delineate the tissue elements, and automatic measure-

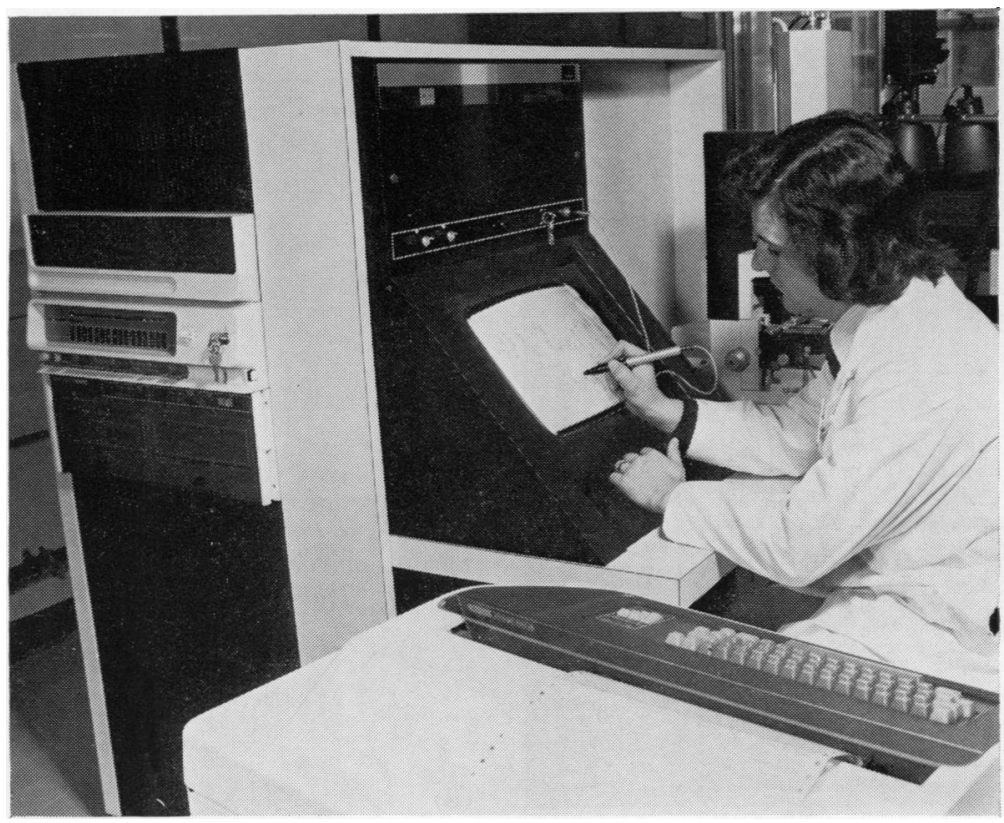

Fig. 1 The observer sits at the console, amends the image of the biopsy, and uses the adjacent keyboard to activate the specific programme required. 


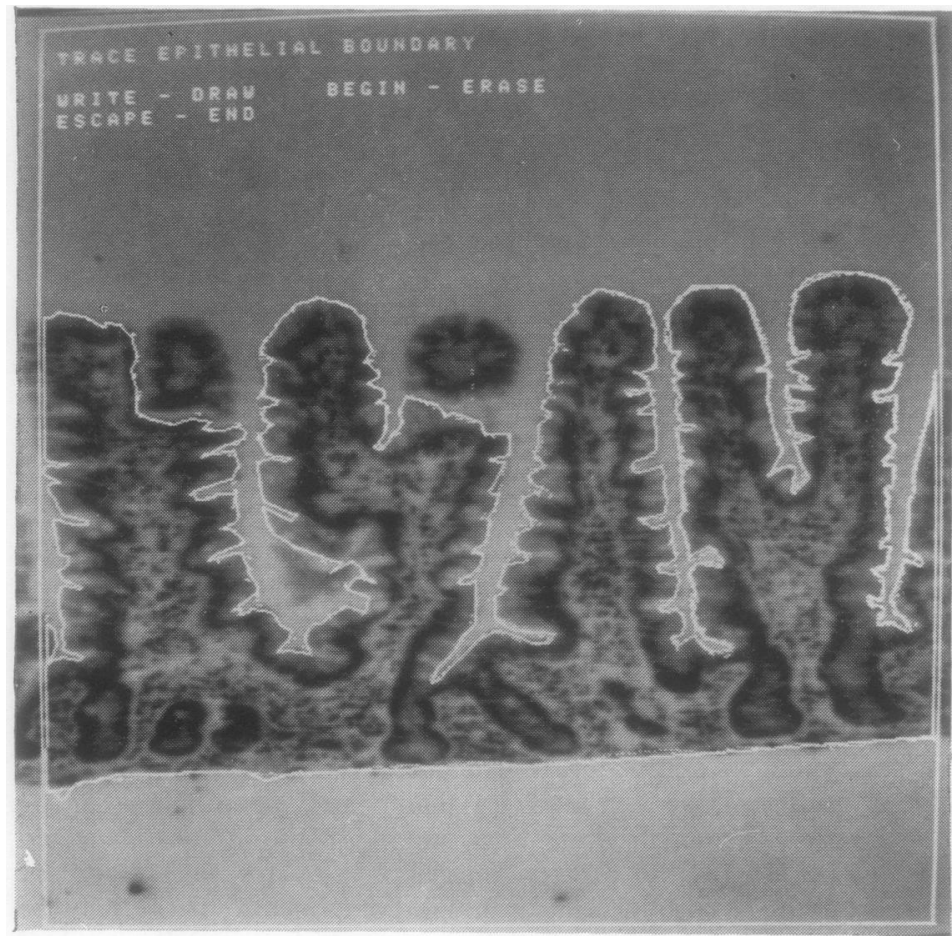

(A)

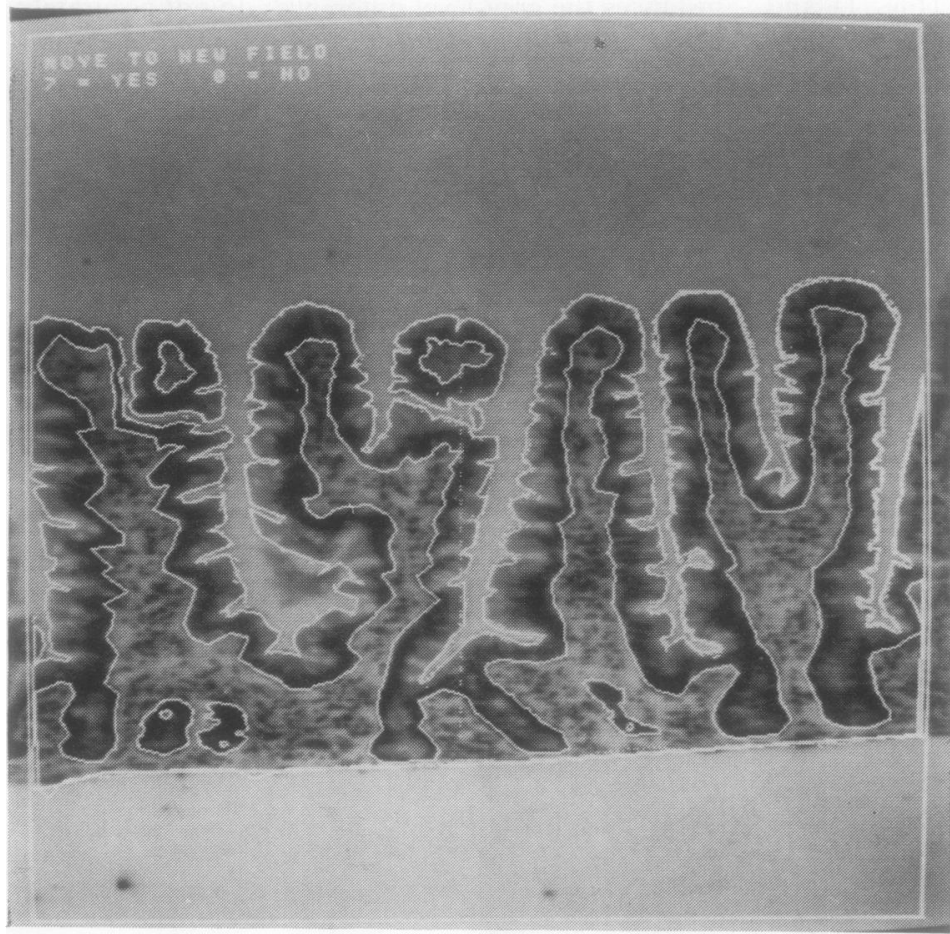

Fig. 2 (A and B) The observer responds to the 'prompt' of the monitor and defines the mucosa with the 'light-pen'. 


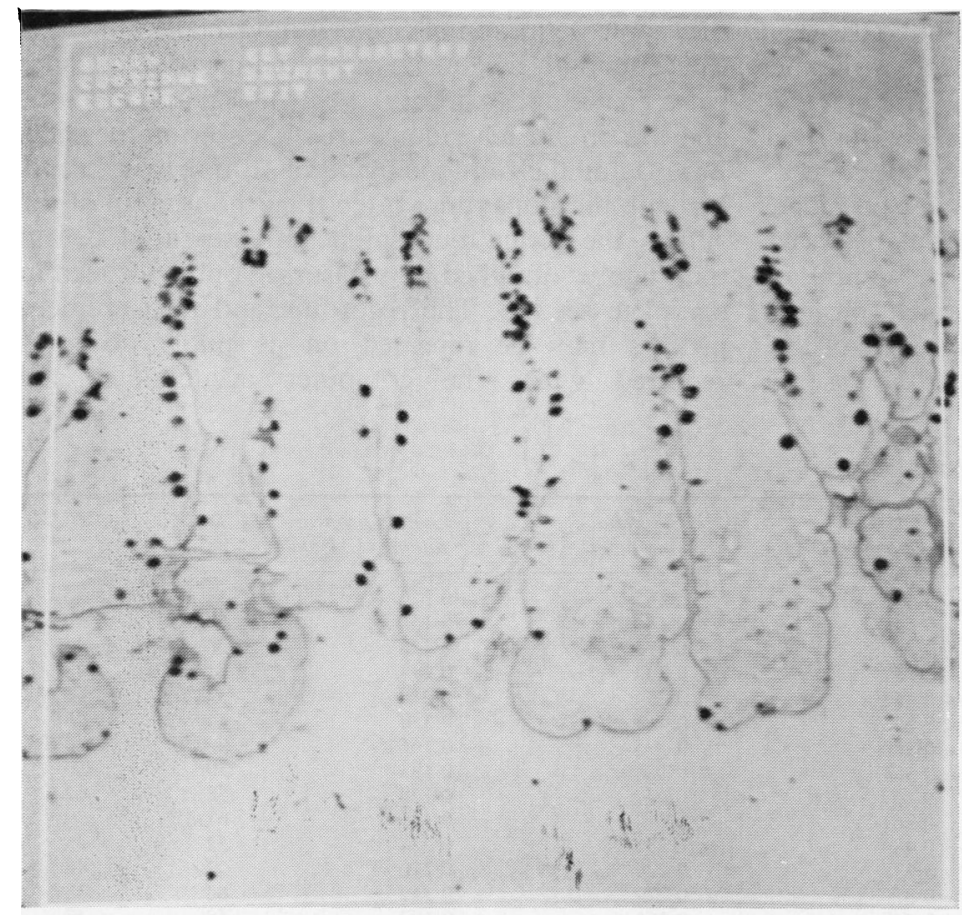

(A)

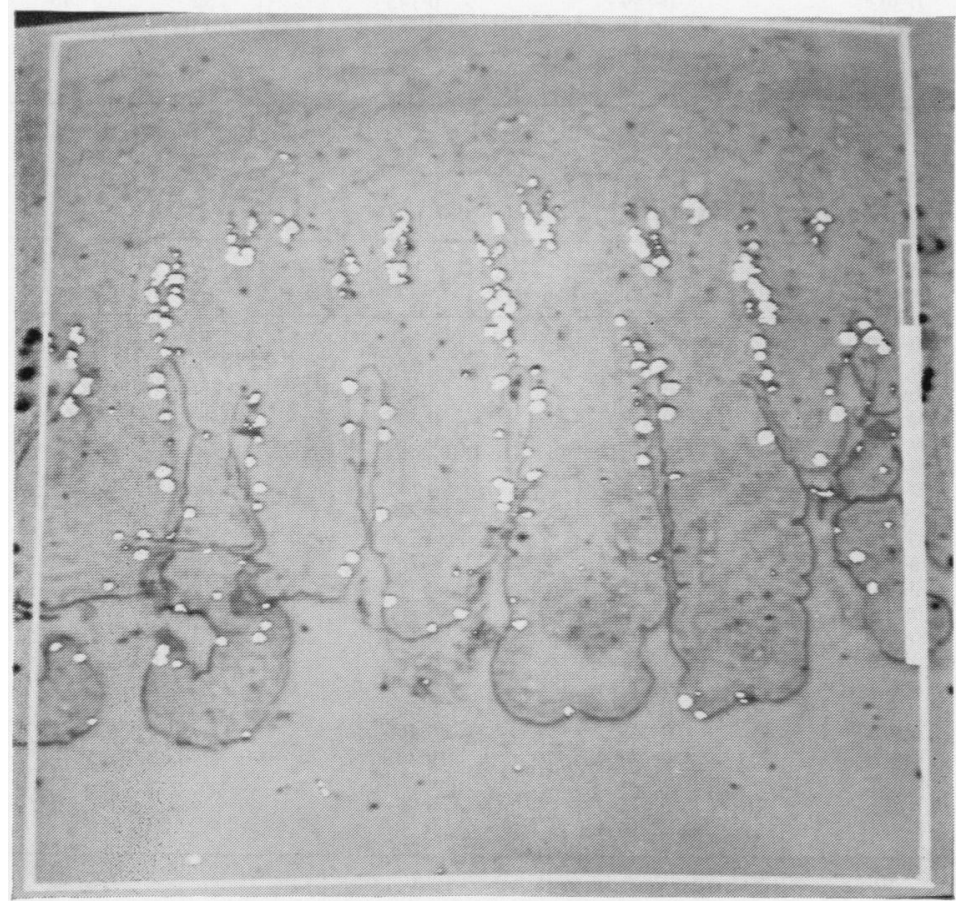

Fig. 3 Within the frame the images of mucus cells stained by PA-thionin-Schiff are displayed $(\mathrm{A})$ and the binary images counted (B). Debris and artefacts may be 'edited' out by 'light-pen' or excluded by size filter. 
ment of these components is therefore not possible. The observer may then again interact with the 'light-pen', defining the structures of interest for analysis. Finally, direct linear measurements on the image such as crypt depth, mucosal thickness, villous height, and enterocyte height may be made simply by indicating the end points of the distances required for measurement. The crypt depth is measured as the distance between the open 'mouth' of a crypt seen in a section through the centre of the crypt to the basement membrane zone at the base of the crypt. Definition of crypts is not usually difficult. ${ }^{6}$ The mucosal height is measured as the distance between the upper border of the muscularis mucosae and the tip of each villous structure seen in the slide. Because of the random plane of section which cuts through the slope more often than the true tip of the villous the mean mucosal height measured is less than figures obtained by measuring only villi seen in complete section. The recording and measurement process may be repeated on as many fields as required while the computer accumulates the

Table 1 Measurements in 20 normal jejunal biopsies

\begin{tabular}{|c|c|c|c|c|c|c|c|c|}
\hline No. & $\begin{array}{l}\text { Mean mucosal } \\
\text { height }(A)(\mu)\end{array}$ & $\begin{array}{l}\text { Mean crypt } \\
\text { depth }(B)(\mu)\end{array}$ & $A / B$ & $\begin{array}{l}\text { Mucosal } \\
\text { volume }(C)^{*}\left(\mathrm{~mm}^{3}\right)\end{array}$ & $\begin{array}{l}\text { Epithelial } \\
\text { volume }(D)\left(\mathrm{mm}^{3}\right)\end{array}$ & $\begin{array}{l}\text { Lamina propria } \\
\text { volume }(E)\left(\mathrm{mm}^{3}\right)\end{array}$ & $D / C \%$ & $E / C^{\circ} \%$ \\
\hline 1 & 520 & 181 & $2 \cdot 87$ & 0.492 & 0.265 & 0.226 & 54 & 46 \\
\hline 3 & 335 & 83 & $4 \cdot 04$ & 0.309 & 0.173 & 0.138 & 56 & 44 \\
\hline 4 & 437 & 89 & 4.91 & 0.381 & $0 \cdot 202$ & 0.194 & 51 & 49 \\
\hline 5 & 390 & 80 & $4 \cdot 88$ & 0.469 & $0 \cdot 254$ & 0.214 & 54 & 46 \\
\hline 6 & 431 & 81 & $5 \cdot 32$ & 0.763 & 0.413 & $0 \cdot 350$ & 54 & 46 \\
\hline 8 & 410 & 95 & $4 \cdot 32$ & 0.367 & $0 \cdot 184$ & 0.183 & 50 & 50 \\
\hline 9 & 553 & 91 & 6.08 & 0.409 & 0.237 & 0.173 & 58 & 42 \\
\hline 10 & 387 & 120 & $3 \cdot 23$ & 0.361 & 0.218 & 0.149 & 61 & 39 \\
\hline 11 & 517 & 98 & $5 \cdot 28$ & 0.489 & 0.255 & $0 \cdot 234$ & 52 & 48 \\
\hline 12 & 464 & 128 & 3.63 & 0.438 & 0.229 & 0.210 & 52 & 48 \\
\hline 13 & 507 & 83 & $6 \cdot 11$ & 0.370 & 0.229 & 0.142 & 62 & 38 \\
\hline 14 & 371 & 78 & $4 \cdot 76$ & 0.448 & $0 \cdot 261$ & $0 \cdot 187$ & 58 & 42 \\
\hline 15 & 342 & 109 & $3 \cdot 14$ & 0.310 & 0.157 & 0.153 & 51 & 49 \\
\hline 16 & 477 & 83 & $5 \cdot 75$ & 0.439 & $0 \cdot 266$ & 0.174 & 60 & 40 \\
\hline 18 & 323 & 84 & 3.85 & 0.353 & 0.201 & 0.152 & 57 & 43 \\
\hline 19 & 388 & 95 & $4 \cdot 08$ & 0.318 & 0.181 & 0.137 & 57 & 43 \\
\hline 20 & 414 & 131 & $3 \cdot 16$ & 0.303 & 0.159 & $0 \cdot 145$ & 52 & 48 \\
\hline Mean & $426 \cdot 4$ & 103 & $4 \cdot 3$ & 0.405 & 0.224 & 0.181 & 55 & 45 \\
\hline \multicolumn{2}{|c|}{$\begin{array}{l}\text { Standard } 65 \\
\text { deviation }\end{array}$} & 25 & 1.0 & 0.1 & 0.05 & 0.04 & $3 \cdot 5$ & $3 \cdot 0$ \\
\hline
\end{tabular}

*Volumes related to $/ \mathrm{mm}^{2}$ of muscularis mucosae.

Table 2 Measurements in 18 jejunal biopsies from untreated patients with coeliac disease

\begin{tabular}{|c|c|c|c|c|c|c|c|c|}
\hline No. & $\begin{array}{l}\text { Mean mucosal } \\
\text { height }(A)(\mu)\end{array}$ & $\begin{array}{l}\text { Mean crypt } \\
\text { depth }(B)(\mu)\end{array}$ & $A / B$ & $\begin{array}{l}\text { Mucosal } \\
\text { volume }(C)^{*}\left(\mathrm{~mm}^{3}\right)\end{array}$ & $\begin{array}{l}\text { Epithelial } \\
\text { volume }(D)\left(\mathrm{mm}^{3}\right)\end{array}$ & $\begin{array}{l}\text { Lamina propria } \\
\text { volume }(E)\left(\mathrm{mm}^{3}\right)\end{array}$ & $D / C \%$ & $E / C^{\circ}$ \\
\hline 1 & 654 & 322 & $2 \cdot 03$ & 0.445 & $0 \cdot 174$ & 0.271 & 39 & 61 \\
\hline 2 & 495 & 408 & $1 \cdot 21$ & 0.523 & 0.199 & $0 \cdot 324$ & 38 & 62 \\
\hline 3 & 334 & 304 & $1 \cdot 10$ & $0 \cdot 368$ & $0 \cdot 124$ & $0 \cdot 243$ & 34 & 66 \\
\hline 4 & 350 & 318 & $1 \cdot 10$ & 0.434 & $0 \cdot 140$ & $0 \cdot 294$ & 32 & 68 \\
\hline 5 & 395 & 353 & $1 \cdot 12$ & 0.417 & 0.151 & $0 \cdot 265$ & 36 & 64 \\
\hline 6 & 320 & 316 & 1.01 & 0.329 & 0.118 & 0.210 & 36 & 64 \\
\hline 7 & 311 & 248 & $1 \cdot 25$ & $0 \cdot 274$ & 0.094 & 0.179 & 34 & 66 \\
\hline 8 & 387 & 366 & $1 \cdot 06$ & $0 \cdot 383$ & $0 \cdot 170$ & 0.214 & 44 & 56 \\
\hline 9 & 325 & 287 & $1 \cdot 13$ & $0 \cdot 318$ & 0.116 & 0.202 & 37 & 63 \\
\hline 10 & 308 & 297 & 1.03 & 0.327 & 0.121 & $0 \cdot 206$ & 37 & 63 \\
\hline 11 & 387 & 335 & $1 \cdot 16$ & $0 \cdot 700$ & 0.209 & 0.489 & 30 & 70 \\
\hline 12 & 600 & 455 & $1 \cdot 32$ & 0.516 & 0.183 & 0.321 & 35 & 65 \\
\hline 13 & 310 & 257 & $1 \cdot 21$ & 0.285 & 0.092 & 0.192 & 33 & 67 \\
\hline 14 & 393 & 251 & 1.57 & 0.410 & 0.155 & 0.254 & 38 & 62 \\
\hline 15 & 344 & 318 & $1 \cdot 08$ & 0.286 & 0.099 & 0.187 & 35 & 65 \\
\hline 16 & 413 & 355 & $1 \cdot 16$ & 0.495 & 0.211 & $0 \cdot 284$ & 43 & 57 \\
\hline 17 & 530 & 473 & $1 \cdot 12$ & 0.675 & 0.208 & 0.466 & 30 & 70 \\
\hline 18 & 474 & 433 & 1.09 & 0.428 & 0.178 & $0 \cdot 250$ & 42 & 58 \\
\hline Mean & 409 & 325 & $1 \cdot 3$ & 0.418 & $0 \cdot 154$ & 0.254 & 37 & 63 \\
\hline $\begin{array}{l}\text { Standard } \\
\text { deviation }\end{array}$ & 102 & 76 & 0.4 & 0.11 & 0.03 & 0.08 & 4 & 5 \\
\hline
\end{tabular}

*Volumes related to $/ \mathrm{mm}^{2}$ of muscularis mucosae. 
measurements. When enough fields have been measured the user asks the computer to evaluate the quantities measured. This evaluation may be made as simple values or in terms of ratios with various denominators-lengths of muscularis mucosae, area of mucosa, area of epithelium or stroma - as may be required by the investigation.

\section{(A)}

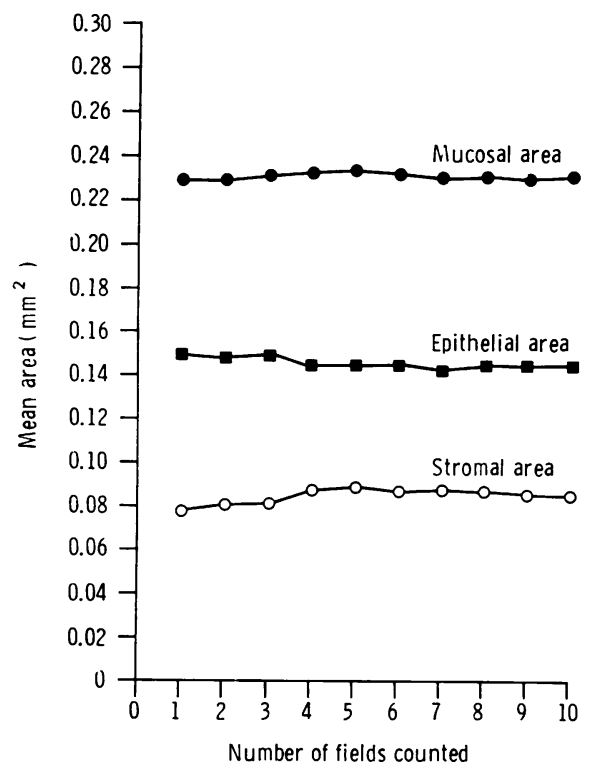

(B)

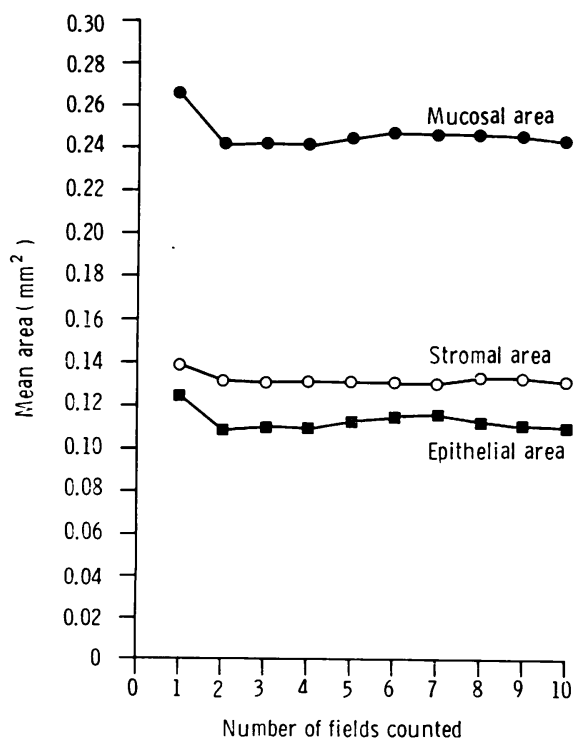

Fig. 4 Cumulative mean values of areas measured in jejunal mucosa for normal mucosa (A) and coeliac mucosa (B).
Results

Results from normal jejunal biopsies and from patients with coeliac disease are presented in Tables 1 and 2 . Such measurements are obtained easily and without observer fatigue. A single biopsy may be analysed in about 10 minutes. The results are consistently reproducible by single or multiple observers. We have employed the method of cumulative means ${ }^{13}$ and after measurement of two fields the epithelial and stromal area values are constant (Fig. 4). The results obtained by the technique are a direct measurement of tissue component present in the tissue and are not an inference based on statistical methods as in pointcounting techniques.

\section{Discussion}

Objective measurement is important in routine diagnostic pathology and in the full assessment of each biopsy so that comparisons can be made between different biopsies in a single patient or between biopsies in groups of patients. Much work has been done using stereological techniques applied to jejunal mucosal biopsies, ${ }^{45}$ but this approach is limited because it involves point counting or intercept techniques which are tedious and tiring for the observer. Moreover, in many cases the tissue elements are not randomly distributed but are anisotropic, and the commonly used stereological methods may be inappropriate. The use of computeraided microscopy offers a possible solution. It permits rapid measurement of defined tissue elements based on a simple graphical technique. Moreover, by examing all the areas within a field, this method yields direct measurements of complex shapes rather than estimates inferred by statistical estimation.

The analysis of a microscopic image by computer is based on grey-level equivalents of the colour and shades within the histological preparation. In the past, commercially available image analysis systems have relied on structural analysis performed by examining independently grey levels at each point in the image. While this has proved practical in many fields such as geology and metallurgy, it is found that the restrictions of the method make the separation of images into the structural components difficult in complex biomedical applications.

Two approaches may be used to solve the problem. Separation of the tissue element images may be made easier by the use of selective staining, which emphasises tissue and cellular tonal contrasts. Thus enterochromaffin cells and their precursors may be effectively delineated by the argyrophil reaction. 
However, the selective stains may not be the usual ones chosen for microscopy by the pathologist, and this may require modification of his techniques. The mucus content of a section is clearly shown by the periodic acid-Schiff reaction when viewed down a microscope; the magenta staining of mucus, however, produces poor grey-level contrasts and is unsuitable for the definition of mucus content in automatic image analysis. Use of an alternative periodic acid-thionin-Schiff reaction, however, produces dark blue staining of the mucus, giving excellent grey-level contrast and discrimination. Selective staining is an important manner of extending structural analysis of the grey-level image but is limited in its application.

The second generation of commercially available image analysis systems, of which the Magiscan Image Analysis system is one, offers a different approach. In these, the analysis of the image may be based on interactive definition of tissue elements by the observer as well as by automatic methods. We have found that automatic methods of image analysis based solely on grey-level thresholding have been unable to detect the components of jejunal mucosal biopsies in a satisfactory manner. However, the technique of interactive graphics permits descriptions of the image components to be passed to the computer, which then carries out direct measurements of areas within defined curves and lengths of curves. This system when applied to the examination of jejunal biopsies is rapid and efficient and gives easily reproduced results. Definition of the epithelium and stroma is made by the 'light-pen', and selective staining further aids the definition of particular tissue elements. The values are recorded in terms of measured values within the area of the section such as mucosal thickness, crypt depth, mucosal area, epithelial area, or stromal area rather than in merely proportional terms as is usual in grid counts. The method is now in routine use in this laboratory and is applicable with simple modification of the programme to other tissues besides jejunum.

The results in Tables 1 and 2 show significant differences in the values from normals and from patients with untreated coeliac disease which allow sharp separation of the two groups and provide suitable parameters to follow sequentially as a response to therapy. There is no significant difference in the mean mucosal heights between the groups but the crypt depth in coeliac patients is greatly increased and the ratio $\frac{\text { mean mucosal height }}{\text { mean crypt depth }}$ emphasises this difference, as well as indicating the 'flatness' of the mucosa in untreated coeliac patients.
The mucosal volume related to a standard $1 \mathrm{~mm}^{2}$ of muscularis mucosae is similar in the two groups but the proportions of epithelium and lamina propria show marked changes in coeliac patients. There is a loss in the epithelial volume fraction, and this is matched by an increase in the lamina propria. This increase is greater than that observed by Meinhardt et al. ${ }^{6}$ although their measurements were in children.

Although large image analysis machines have many potential applications it is evident that the capital costs will restrict their use to teaching hospitals or to laboratories partly supported by research funds. Nevertheless the method of 'interactive graphics' described illustrates an approach that can be developed for use in more restricted and cheaper computer systems. These can be applied more generally to other tissues in diagnostic histopathology and allow measurement as a matter of course in day-to-day work.

\section{References}

${ }^{1}$ Doniach I, Shiner M. Duodenal and jejunal biopsies. II Histology. Gastroenterology 1957;33:71-86.

${ }^{2}$ Shiner M, Doniach I. Histopathologic studies in steatorrhea. Gastroenterology 1960;38:419-40.

${ }^{3}$ Roy-Choudhury D, Cooke WT, Tan DT, Banwell JG, Smits BJ. Jejunal biopsy: Criteria and significance. Scand J Gastroent 1966;1:57-74.

${ }^{4}$ Dunnill MS, Whitehead R. A method for the quantitation of small intestinal biopsy specimens. J Clin Pathol 1972;25:243-6.

5 Wright SG, Tomkins AM. Quantitative histology in giardiasis. J Clin Pathol 1978;31:712-6.

${ }^{6}$ Meinhard EA, Wadbrook DG, Risdon RA. Computer card morphometry of jejunal biopsies in childhood coeliac disease. J Clin Pathol 1975;28:85-93.

${ }^{7}$ Chapman BL, Henry K, Paice F, Stewart JS, Coghill NF. A new technique for examining intestinal biopsies. Gut 1973;14:905-9.

${ }^{8}$ Rosenfeld A, Kak AC. Digital Picture Processing. New York: Academic Press, 1976.

${ }^{9}$ Scott KWM, Hoy J. The cross sectional area of diaphragmatic muscle fibres in emphysema, measured by an automated image analysis system. $J$ Pathol 1976;120:121-8.

${ }^{10}$ Langston C, Thurlbeck WM. The use of simple image analysers in lung morphometry. $J$ Microsc 1978; 114:89-99.

${ }^{11}$ Grimelius L, Åkerström G, Johansson H, Lundqvist H. Estimation of parenchymal cell content of human parathyroid glands using the image analyzing computer technique. Amer J Pathol 1978;93:793-800.

12 Crocker J, Curran RC. A study of nuclear diameters in lymph node imprints using the Zeiss Microvideomat. $J$ Clin Pathol 1979;32:670-4.

${ }^{13}$ Dunnill MS. Quantitative methods in histology. In: Dyke SC, ed. Recent Advances in Clinical Pathology, Series V. London: Churchill, 1968:401-16. 


\section{Addendum}

Since this paper was submitted the programme has been modified with the help of Joyce Loebl so that a contour tracing routine automatically delineates the outer border of the epithelial cells, replacing the need for manual tracing at this stage. Automatic tracing of the epithelial cell-stromal interface is more complex and has not yet been achieved.

Requests for reprints to: Dr G Slavin, Northwick Park Hospital and Clinical Research Centre, Harrow, Middx, UK.

\section{Reports and Bulletins prepared by the Association of Clinical Biochemists}

The following reports and bulletins are published by the Association of Clinical Biochemists. They may be obtained from The Publishing Department, British Medical Journal (ACB Technical Bulletins), BMA House, Tavistock Square, London WC1H 9JR. Overseas readers should remit by British Postal or Money Order.

SCIENTIFC REVIEWS (price $£ 1 \cdot 00 / \$ 2.00$ each)

1 The assessment of thyroid function March 1971 F V FLYNN and $J$ R HOBBS

2 Renal function tests suitable for olinical practice January 1972 F L MITCHeLL, N VEALL, and R W E WATTS

3 Biochemical tests for the assessment of fetoplacental function May 1975 C E WILDE and R E OAKEY

4 Test of exocrine pancreatic function March 1977 A H GOWENLOCK

5 Assay of cholinesterase in clinical chemistry March 1979 ELSIE SILK, J KING, and MARY WHITTAKER

TECHNICAL BULLETINS (price $£ 1 \cdot 00 / \$ 2.00$ each)

22 Bilirubin standards and the determination of bilirubin by manual and technicon AutoAnalyzer methods January 1971 BARBARA BILLING, RUTH HASLAM, and N WALD

23 Interchangeable cells for spectrophotometers and fluorimeters September 1971 S S BROWN and A H GOWENLOCK

24 Simple tests to detect poisons March 1972 B w MEADE et al.

25 Blood gas analysers May 1972 K DrxoN

26 Kits for enzyme activity determination September 1972 S B ROSALKI and D TARLOW

27 Assessment of pumps suitable for incorporation into existing continuous flow analytical systems November 1972 A FLECK et al.

28 Routine clinical measurements of transferrin in human serum September 1973 K DIXON
29 Control materials for clinical biochemistry (5th edition) September 1973 J F STEVENS

30 Notes on the quality of performance of serum cholesterol assays September 1973 s S BROWN

31 Determination of uric acid in blood and in urine July 1974 R W E WATTS

32 A survey of amino acid analysers readily available in the United Kingdom September 1974 J E CARLYLE and P PURKISS

33 Definitions of some words and terms used in automated analysis November 1974 A FLECK, R ROBINSON, S S BROWN, and J R HOBBS

34 Measurement of albumin in the sera of patients January 1975 LINDA SLATER, P M CARTER, and J R HOBBS

35 Investigation of the validity of temperature correction factors for serum aspartate and alanine transaminases March 1975 S B ROSALKI et al.

36 Factors influencing the assay of creatinine November 1975 J G H COOK

37 A survey of enzyme reaction rate analysers readily available in the United Kingdom July 1977 R A SAUNDERS and $R$ F BURNS

38 Transport of specimens for clinical chemistry analysis November 1977 P WILDING, J F ZILVA, and C E WILDE

39 A scheme for the evaluation of diagnostic kits May 1978 P H LLOYD

40 A practical guide to gamma-counting in radioimmunoassay January 1980 C E WILDE and D OTTEWELL 